\title{
Expanding the application of non-invasive prenatal testing in the detection of foetal chromosomal copy number variations
}

\author{
Chaohong Wang ${ }^{1}$, Junxiang Tang ${ }^{1}$, Keting Tong ${ }^{1}$, Daoqi Huang ${ }^{1}$, Huayu Tu' ${ }^{1}$ Qingnan Li ${ }^{2}$ and Jiansheng Zhu1*
}

\begin{abstract}
Purpose: The aim of this study was to assess the detection efficiency and clinical application value of non-invasive prenatal testing (NIPT) for foetal copy number variants (CNVs) in clinical samples from 39,002 prospective cases.

Methods: A total of 39,002 pregnant women who received NIPT by next-generation sequencing (NGS) with a sequencing depth of $6 \mathrm{M}$ reads in our centre from January 2018 to April 2020 were enrolled. Chromosomal microarray analysis (CMA) was further used to diagnose suspected chromosomal aneuploidies and chromosomal microdeletion/ microduplication for consistency assessment.

Results: A total of 473 pregnancies (1.213\%) were positive for clinically significant foetal chromosome abnormalities by NIPT. This group comprised 99 trisomy 21 (T21, 0.254\%), 30 trisomy 18 (T18, 0.077\%), 25 trisomy 13 (T13, 0.064\%), 155 sex chromosome aneuploidy (SCA, 0.398\%), 69 rare trisomy (0.177\%), and 95 microdeletion/microduplication syndrome (MMS, 0.244\%) cases. Based on follow-up tests, the positive predictive values (PPVs) for the T21,T18, T13, SCA, rare trisomy, and MMS cases were calculated to be $88.89 \%, 53.33 \%, 20.00 \%, 40.22 \%, 4.88 \%$, and $49.02 \%$, respectively. In addition, the PPVs of CNVs of $<5 \mathrm{Mb}, 5-10 \mathrm{Mb}$, and $>10 \mathrm{Mb}$ were $54.55 \%, 38.46 \%$, and $40.00 \%$, respectively. Among the 95 cases with suspected CNVs, 25 were diagnosed as true positive and 26 cases as false positive; followup prenatal diagnosis by CMA was not performed for 44 cases. Moreover, among the 25 true positive cases, 10 were pathogenic, 3 were likely pathogenic, and 12 were of uncertain significance.
\end{abstract}

Conclusion: NIPT is not only suitable for screening T21, T18, T13, and SCA but also has potential significance for CNV detection. As combined with ultrasound, extended NIPT is effective for screening MMS. However, NIPT should not be recommended for whole-chromosome aneuploidy screening.

Keywords: Non-invasive prenatal testing (NIPT), Chromosomal aneuploidy, Chromosomal microdeletion/ microduplication, Copy number variation (CNV), Chromosomal microarray analysis (CMA)

\section{Introduction}

Since the first detection of cell-free foetal DNA (cffDNA) in the plasma of pregnant women in 1997 [1], noninvasive prenatal testing (NIPT) detection for foetal

\footnotetext{
*Correspondence: 26321650@qq.com

${ }^{1}$ Affiliated Maternity and Child Health Hospital of Anhui Medical

University, Maternity and Child Health Hospital of Anhui Province, Hefei,

China

Full list of author information is available at the end of the article
}

chromosomal aneuploidy evaluation via extraction of cffDNA from maternal peripheral blood has been widely used in clinical practice in more than 60 countries. As an alternative screening method, NIPT is proven to have very high sensitivity and specificity for detecting common chromosomal aneuploidies, such as trisomy 21 (T21), trisomy 18 (T18), and trisomy 13 (T13), with low false positive and false negative rates [2-4]. Interestingly, recent studies have shown that in addition to T21, T18, 
and T13, NIPT is effective at detecting sex chromosome abnormalities (SCAs) [5, 6]. Indeed, the American College of Medical Genetics suggests that NIPT is the most sensitive method for prenatal screening of trisomy 21,18 , and 13.

Microdeletion/microduplication syndromes (MMS), which are due to copy number variations (CNVs), are another major inheritance factor that causes birth defects. CNVs are widespread in the human genome. The incidence of pathogenic CNVs in the normal population can reach $1.0-1.7 \%$, which is much higher than the incidence of T21 (0.13-0.17\%) [7]. Recently, the further development and expansion of NIPT have focused on MMS. However, the accuracy and reliability of MMS detection by NIPT is challenging because of the influence of some biological factors, such as a low content of cffDNA, maternal chromosomal abnormalities, and confined placental mosaicism [8]. Many attempts have been made to resolve these issues. Further sequencing or high-density single-nucleotide polymorphism-targeting methods have proven the feasibility of MMS detection by NIPT [9-11]. In China, Chen et al. [12] and Liang et al. [13] confirmed that NIPT is suitable not only for common chromosome aneuploidy detection but also for MMS detection. However, many problems and challenges in clinical practice remain. For example, the number of clinical samples remains insufficient, and MMS classification and follow-up are not ideal, which limits the largescale application of MMS detection in NIPT.

This study aimed to assess the detection efficiency and clinical application value of NIPT for foetal copy number variants (CNVs) in clinical samples from 39,002 prospective cases, comprising the largest population study in East China. The findings of this study might help to improve diagnostic accuracy while reducing cost and improving maternal and prenatal health care.

\section{Methods}

\section{Subjects}

Within a 28-month period (January 2018 to April 2020), 39,002 pregnant women (age: 18-48 years old; gestational week: $12^{+0} \sim 26^{+5}$ ) in our centre were enrolled for this NIPT trial by NGS with a sequencing depth of $6 \mathrm{M}$ reads. All patients underwent pretest counselling to inform them of the sample type, test method, test contents, test limitations, sensitivity and specificity of NIPT, etc. Ultrasound was required to determine the number of foetuses and to exclude structurally abnormal foetuses before testing. All high-risk pregnant women were advised to undergo amniocentesis and confirmatory prenatal diagnosis. We conducted a series of tests, such as foetal ultrasound and clinical examination of new-borns, for low-risk cases and patients with positive results who refused a prenatal diagnosis. All cases with a positive prenatal diagnosis were scheduled for genetic counselling. Among the 39,002 pregnant women, 7968 $(20.43 \%)$ were older than 35 years old. In $832(2.13 \%)$ of the women, abnormal single ultrasonic soft indexes, such as unilateral or bilateral choroid plexus cysts, ventricular bright spots, and slightly widened lateral ventricles, were detected. Critical thickening of the NT value was found in 237 cases $(0.61 \%)$. In total, 5313 patients $(13.62 \%)$ had a high risk of serological screening, 11,351 (29.10\%) had a critical risk of serological screening, $74(0.19 \%)$ had other causes, and 13,227 (33.91\%) had no clinical indications but required NIPT detection with independent requirements.

\section{Indications for NIPT}

The inclusion criteria were as follows: maternal serological screening critical-risk value $(1 / 1000 \leq \mathrm{T} 21<1 / 270$, $1 / 1000 \leq \mathrm{T} 18<1 / 350)$, maternal serological screening high-risk value ( $\mathrm{T} 21 \geq 1 / 270, \mathrm{~T} 18 \geq 1 / 350$ ), contraindications of prenatal diagnosis, missed serological screening or requested NIPT, advanced maternal age (35 years or older at the expected due date), abnormal single ultrasonic soft indexes such as unilateral or bilateral choroid plexus cyst, ventricular bright spot, slightly widened lateral ventricle, critical thickening of the NT value $(2.0 \leq \mathrm{NT} \leq 3.0)$, IVF, or twin pregnancy.

Exclusion criteria for NIPT were as follows: not in gestational week $12+0 \sim 26+5$, chromosome abnormality in one of the parents, ultrasonography showing structurally abnormal foetuses, family history of genetic diseases or high-risk of genetic diseases, malignant tumour during pregnancy, allogeneic blood received within one year, exogenous DNA introduced within 4 weeks, and transplantation and stem cell therapy, among others.

Chromosomal aneuploidies suspected by NIPT were confirmed by karyotype analysis. In pregnancies with copy number variants shown by NIPT, we suggest the application of CMA at prenatal diagnosis. Informed written consent was obtained from all participants for the use of their peripheral blood and amniotic fluid samples for the current analyses.

\section{Collection and treatment of blood samples}

Maternal peripheral blood samples $(5 \mathrm{~mL})$ were collected in EDTA tubes, fully mixed, and stored temporarily at $4{ }^{\circ} \mathrm{C}$. Samples were excluded if haemolysis or storage occurred beyond eight hours before plasma separation. The blood sample was centrifuged at $4{ }^{\circ} \mathrm{C}$ and $1600 \times g$ for $10 \mathrm{~min}$, and the plasma was collected carefully and dispensed into 2.0-mL Eppendorf tubes. The plasma was centrifuged again at $4{ }^{\circ} \mathrm{C}$ and $16,000 \times g$ for another $10 \mathrm{~min}$. The upper plasma was carefully divided into 
new 2.0-mL Eppendorf tubes, with each tube containing approximately $600 \mathrm{uL}$ plasma, which was stored at -80 ${ }^{\circ} \mathrm{C}$. Repeated freezing and thawing before the experiment, as previously reported, were avoided [14].

\section{NIPT with the BGISEQ-500 sequencing platform}

DNA extraction, library construction, and sequencing were performed according to the standard protocol of Human Molecular Genetics Guidelines at Anhui Maternal and Child Health Care Hospital. Maternal plasma $(200 \mu \mathrm{L})$ was used for cell-free foetal DNA extraction with a BGISP-300 (BGI, Shenzhen, China) and Nucleic Acid Extraction Kit (BGI, Shenzhen, China). After DNA extraction, the DNA was subjected to end repair by end repair enzymes under the following conditions: $37^{\circ} \mathrm{C}$ for $10 \mathrm{~min}$ and $65{ }^{\circ} \mathrm{C}$ for $15 \mathrm{~min}$, followed by adaptor ligation at $23^{\circ} \mathrm{C}$ for $20 \mathrm{~min}$ with the label adaptor and ligase. After end repair and adaptor ligation, PCR was used to amplify the DNA to the desired concentration with the following cycle conditions: $98{ }^{\circ} \mathrm{C}$ for $2 \mathrm{~min}$, followed by 12 cycles at $98{ }^{\circ} \mathrm{C}$ for $15 \mathrm{~s}, 56{ }^{\circ} \mathrm{C}$ for $15 \mathrm{~s}$, and $72{ }^{\circ} \mathrm{C}$ for $30 \mathrm{~s}$ and a final extension at $72{ }^{\circ} \mathrm{C}$ for $5 \mathrm{~min}$. The DNA amplification products were quantified using a Qubit ${ }^{\circledR}$ 2.0 (Life Tech, Invitrogen, USA) and QubitTM dsDNA HS Assay Kits (Life Tech, Invitrogen, USA); a concentration $\geq 2 \mathrm{ng} / \mu \mathrm{L}$ was regarded as a qualified standard. The volume was calculated according to the concentration of each sample, and each sample of the same mass was mixed by pooling. Double-stranded DNA was thermally denatured after pooling, and cyclic buffer and ligase were added for a cyclization reaction. The DNA circles were used to prepare DNBs by rolling circle replication (RCR). The concentration of DNBs was quantified by a Qubit ${ }^{\circledR}$ 2.0 using QubitTM ssDNA Assay Kits (Life Tech, Invitrogen, USA), and DNB concentrations in the range of $8-40 \mathrm{ng} / \mu \mathrm{L}$ were considered appropriate. The DNBs were loaded onto chips and sequenced using the BGISEQ-500 sequencing platform [14] (BGI, Shenzhen, China). Any sample that failed to meet the quality control criteria was reported as detection failure by NIPT.

The sequence based on NGS was compared with the reference sequence map of the human genome, and the percentage of each chromosome was calculated with Illumina Sequencing Analysis Viewer1.9.1 software. Z and $\mathrm{T}$ values were used to evaluate the actual disease situation of the samples, as previously reported [14]. Interventional prenatal diagnosis was recommended for high-risk pregnant women with NIPT, and the pregnancy outcomes of all cases were followed up.

\section{Karyotype analysis}

Informed written consent was obtained from all participants for the use of their peripheral blood and amniotic fluid samples for the current analyses, and the tests were performed with patient agreement. Amniocentesis and confirmatory prenatal diagnosis were recommended for all high-risk pregnancies. Karyotypes were analysed according to the standard of ISCN (2016) through the process of standardized cell culture, filmmaking, and G-banding.

\section{Chromosomal microarray analysis (CMA)}

Amniotic fluid samples were centrifuged at $4{ }^{\circ} \mathrm{C}$ and $1000 \times g$ for $10 \mathrm{~min}$; the cell pellet was retained for extraction of DNA. A 4- $\mu \mathrm{L}$ aliquot of DNA sample with absorbance (A260/280 nm) at 1.7-1.9 was used, and chromosomal microarrays were detected according to the instructions of Affymetrix CytoScan $750 \mathrm{~K}$ arrays (Thermo Fisher, MA, USA). Data were collected by the GeneChip $^{\mathrm{TM}}$ Scanner 3000 system, and the results were analysed by Chromosome Analysis Suite software.

\section{Results}

\section{Overall NIPT screening results for 39,002 cases}

In 412 cases $(1.056 \%, 412$ per 39,002$)$, blood needed to be drawn again due to a variety of reasons, such as severe haemolysis and coagulation, large fluctuation of the data for chr21, chr18 and chr13, large fluctuation of the data for other chromosomes, SCA, low content of cffDNA $(<5 \%)$, and high DNA concentration. Among these 412 cases, 384 cases $(93.204 \%, 384$ out of 412$)$ were effectively detected after drawing blood again; however, 28 cases $(6.796 \%, 28$ out of 412$)$ were not, suggesting that the detection failure rate of NIPT was $0.072 \%$ (28 out of 39,002).

Among 38,974 cases with effective detection, 473 cases were high-risk, comprising 99 trisomy 21 (T21, 0.254\%), 30 trisomy 18 (T18, 0.077\%), 25 trisomy 13 (T13, 0.064\%), 155 sex chromosomal aneuploidies (SCA, 0.398\%), 69 rare trisomy $(0.177 \%)$, and $95 \mathrm{microdeletion} / \mathrm{microdu}-$ plication syndrome (MMS, $0.244 \%$ ) cases. Of these, 338 patients $(71.459 \%$, 338 out of 473$)$ agreed to follow-up prenatal diagnoses, whereas 135 (28.541\%, 135 out of 473) refused. For low-risk cases and patients with positive results who refused to receive a prenatal diagnosis, we conducted a series of tests, such as foetal ultrasound and clinical examination of new-borns; however, 128 patients were lost to follow-up. After follow-up, we found 1 case of T21 among the NIPT-negative results. The flowchart of the study is illustrated in Fig. 1.

\section{Detection efficiency of T21, T18, and T13 in NIPT}

To evaluate the clinical efficacy of NIPT in this study, we focused on the detection efficiency of T21, T18, and T13 for overall evaluation. There were 154 patients with a high risk of T21, T18, and T13 among 38,974 patients, 


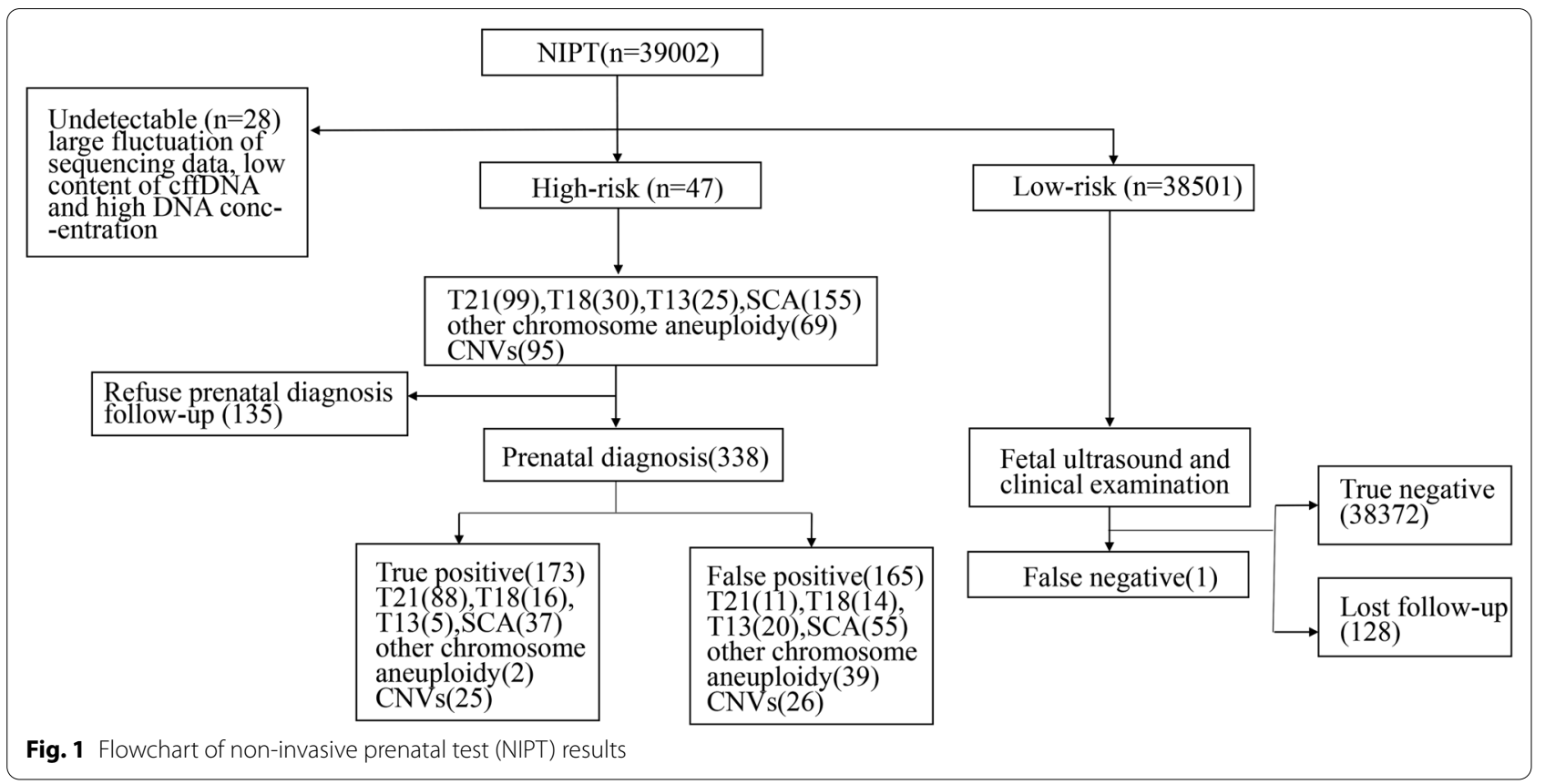

and all were followed up by amniocentesis and karyotype analysis. As shown in Table 1, the positive predictive values (PPVs) of T21, T18, and T13 were 88.89\% (88 out of 99 ), $53.33 \%$ (16 out of 30 ), and $20.00 \%$ (5 out of $25)$, respectively; sensitivities were $98.88 \%, 100.00 \%$, and $100.00 \%$ and specificities $99.97 \%$, 99.96\%, and 99.95\%, respectively. However, because one case of T21 was missed, which was found during follow-up, the negative predictive value (NPV) for T21 was 99.99\% (Table 1).

\section{Detection efficiency of NIPT in screening other chromosome aneuploidies}

After evaluating T21, T18, and T13, we sought to evaluate the occurrence of other chromosomal abnormalities and CNVs. First, we examined SCAs and found the following: (1) 92 patients agreed to follow-up prenatal diagnosis by karyotype analysis, and 37 cases were true positive (PPV: 40.22\%); (2) 71 patients had a high risk of 45 ,X, but only 40 were followed up by amniocentesis and karyotype analysis, and 7 cases were true positive (PPV: $17.50 \%$ ); (3) 39 patients had a high risk of $47, \mathrm{XXY}$, but only 23 were followed up by amniocentesis and karyotype analysis, and 13 cases were true positive (PPV: 56.52\%); (4) 30 patients had a high risk of 47,XXX, but only 18 were followed up by amniocentesis and karyotype analysis, and 10 cases were true positive (PPV: $55.56 \%$ ); (5) 15 patients had a high risk of $47, \mathrm{XYY}$, but only 11 were followed up by amniocentesis and karyotype analysis, and 7 cases were true positive (PPV: 63.64\%). Second, the detection efficiency of NIPT for other chromosomal abnormalities was relatively low. Among 41 cases followed up by amniocentesis and karyotype analysis, only 2 were true positive (PPV: $4.88 \%$ ). The highest incidence rate of other chromosomal abnormalities in this study was for T7 and T16 (13 cases); T8 was found in 12 cases. Unfortunately, in addition to T2, the PPVs of other chromosomal abnormalities, including T7, T8, T16, monosomic 18 (M18), T15, T2, T19, monosomic 21 (M21), T3, T5, T6, T10, and T14, were $0 \%$ (Table 2).

\section{Detection efficiency of NIPT in CNV screening}

MMS, which is due to copy number variations (CNVs), is another major inheritance factor that causes birth defects, and we thus analysed CNVs in NIPT. Among the

Table 1 The detection efficiency of T21, T18, and T13 in NIPT

\begin{tabular}{lllllllll}
\hline NIPT & TP & FP & PPV (\%) & Sensitivity (\%) & TN & FN & NPV (\%) & Specificity (\%) \\
\hline T21 & 88 & 11 & 88.89 & 98.88 & 38,874 & 1 & 99.99 & 99.97 \\
T18 & 16 & 14 & 53.33 & 100 & 100 & 38,944 & 0 & 100 \\
T13 & 5 & 20 & 20 & 38,949 & 0 & 100 & 99.96 \\
\hline
\end{tabular}


Table 2 The detection efficiency of SCA, other chromosome aneuploidy, and CNVs in NIPT

\begin{tabular}{|c|c|c|c|c|c|}
\hline NIPT & Positive & $\mathrm{TP}$ & $\mathrm{FP}$ & Unverified & PPV (\%) \\
\hline SCA & 155 & 37 & 55 & 63 & 40.22 \\
\hline $45, x$ & 71 & 7 & 33 & 31 & 17.50 \\
\hline $47, X X Y$ & 39 & 13 & 10 & 16 & 56.52 \\
\hline $47, X X X$ & 30 & 10 & 8 & 12 & 55.56 \\
\hline $47, X Y Y$ & 15 & 7 & 4 & 4 & 64.64 \\
\hline $\begin{array}{l}\text { Other chromosome ane- } \\
\text { uploidy }\end{array}$ & 69 & 3 & 38 & 28 & 7.32 \\
\hline $\mathrm{T} 7$ & 13 & 0 & 8 (likely placental mosaicism) & 5 & Not estimable \\
\hline T8 & 12 & 0 & 7 (likely placental mosaicism) & 5 & Not estimable \\
\hline T16 & 13 & 0 & 7 (likely placental mosaicism) & 7 & Not estimable \\
\hline M18 & 4 & 0 & 4 & 0 & 0.00 \\
\hline T15 & 6 & 0 & 3 & 3 & 0.00 \\
\hline $\mathrm{T} 2$ & 5 & 2 & 1 & 2 & 66.67 \\
\hline T9/M21 & 5 & 0 & $4(2 / 2)$ & 1 & 0.00 \\
\hline Т3/Т5/T6/Т10/T14 & 11 & 0 & $5(1 / 1 / 1 / 1 / 1)$ & 6 & 0.00 \\
\hline CNV & 95 & 25 & 26 & 44 & 49.02 \\
\hline $\mathrm{CNV}<5 \mathrm{Mb}$ & 42 & 18 & 15 & 9 & 54.55 \\
\hline CNV 5-10 Mb & 25 & 5 & 8 & 12 & 38.46 \\
\hline $\mathrm{CNV}>10 \mathrm{Mb}$ & 28 & 2 & 5 & 21 & 40.00 \\
\hline
\end{tabular}

51 cases for which CMA and/or karyotype analysis could subsequently achieve prenatal diagnosis, 25 were true positive (PPV: 49.02\%) (Table 2 and Fig. 2). Then, we subdivided these 51 cases according to the CNV fragment size. The PPVs of $<5 \mathrm{Mb}, 5-10 \mathrm{Mb}$, and > $10 \mathrm{Mb}$ CNVs were $54.55 \%, 38.46 \%$, and $40.00 \%$, respectively (Table 2 ). To further examine the distribution of true positive $\mathrm{CNVs}$, we classified them by chromosome. Interestingly, the PPVs of CNVs in different chromosomes showed obvious differences. For example, the PPVs of CNVs on chr3 were $100.00 \%$ and on chr 5 were $0 \%$ (Table 3 ). Moreover, through the combination of ACMG standardized analysis and follow-up visits, among the 25 true positive cases, 10 were pathogenic and 3 likely pathogenic; 12 cases were of uncertain significance (Table 4).

\section{Discussion}

As an alternative screening method, NIPT has been shown to have very high sensitivity and specificity for detecting common chromosomal aneuploidies such as $\mathrm{T} 21, \mathrm{~T} 18$, and T13, with low false positive and false negative rates. However, screening of other chromosome aneuploidies and CNVs is still controversial $[15,16]$. In 2016, the ACMG suggested that NIPT is only suitable for screening common chromosomal aneuploidy abnormalities and that positive results need to be verified by invasive prenatal diagnosis [17]. In addition to chromosomal aneuploidies, MMS, which is due to copy number variations (CNVs), is another major inheritance factor that causes birth defects. Indeed, the incidence of MMS in the normal population can reach $1.00 \%-1.70 \%$, which is even higher than the incidence of T21 (0.13-0.17\%). In practice, CMA is a powerful tool for detecting MMS and has been recommended as a primary diagnostic tool for some definite syndromes [18]. Nevertheless, CMA requires invasive sampling, causing unnecessary risks [19], such as miscarriage, preterm birth, and intrauterine infection, and it may thus be rejected by some women. Based on the excellent performance of NIPT in the detection of CNVs, an increasing number of guidelines suggest that it should be applied in the screening of CNVs [20]. Thus, the aim of this study was to assess the detection efficiency and clinical application value of NIPT for CNVs in clinical samples from 39,002 prospective cases and to accumulate experience for subsequent large-scale application.

It has been reported that the PPV range of NIPT is $65-94 \%$ for $\mathrm{T} 21,47-85 \%$ for $\mathrm{T} 18$, and $12-62 \%$ for $\mathrm{T} 13$ [21-23]. In this study, the PPVs of T21, T18 and T13 were $88.89 \%, 53.33 \%$ and $20.00 \%$, respectively, consistent with reported results. Of the 38,974 of 39,002 cases that could be detected by NIPT, cases of T18 and T13 were correctly identified, and the NPVs were both $100 \%$. Only one case of T21 was missed, and the NPV was $99.99 \%$, suggesting that NIPT screening for T21, T18, and T13 displayed excellent accuracy and reliability in this study. In the case of the T21 missed diagnosis, NIPT data showed a low risk of T21. The karyotype using the amniotic fluid sample was 47,XY,+21[67]/46,XY[16]. After induction 

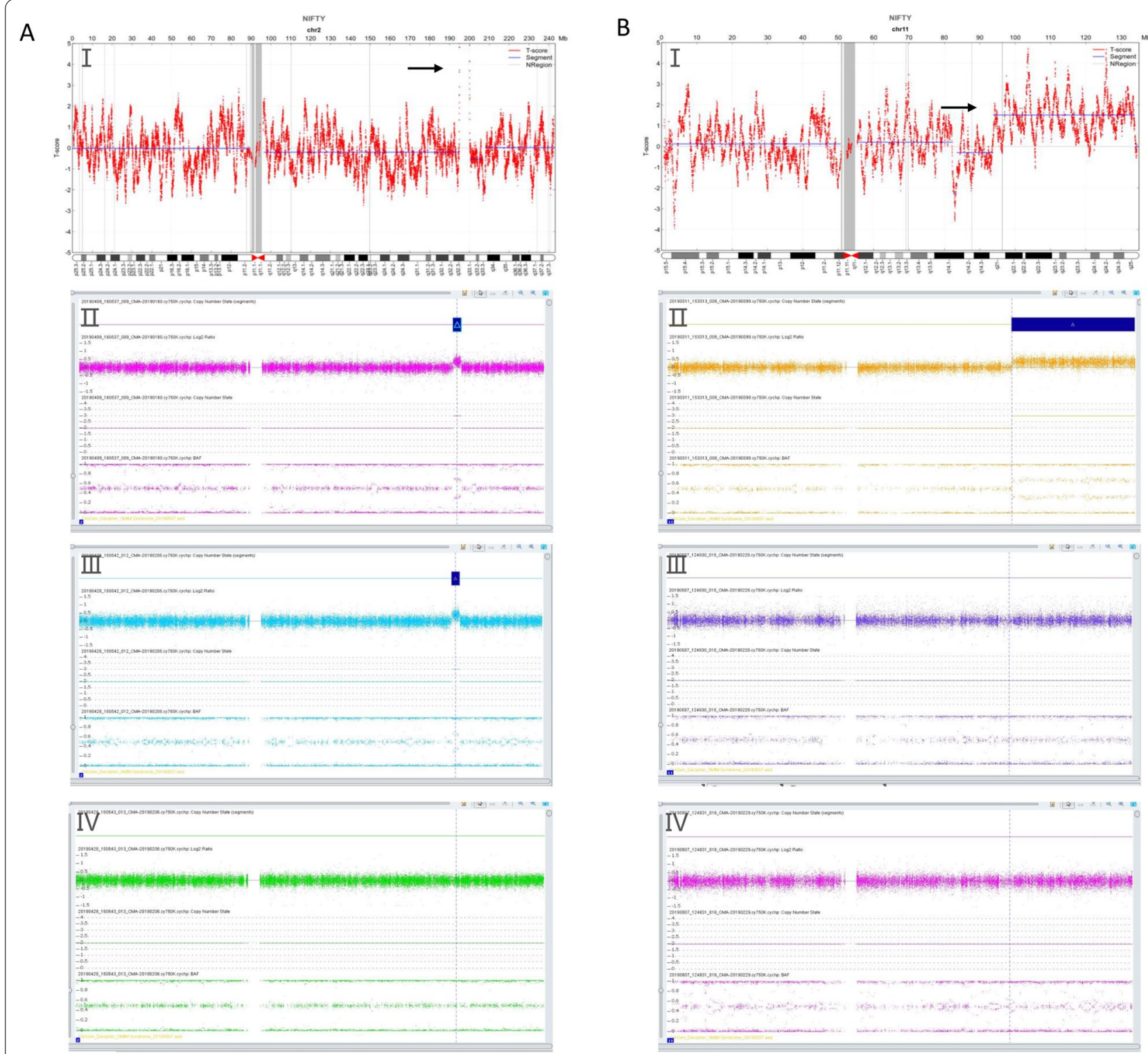

Fig. 2 Comparison of NIPT and CMA in detecting duplications. AI NIPT of peripheral blood from the pregnant woman. The genomic position is shown on the $x$-axis and the count-based T-score is shown on the $y$-axis, arrow indicates the sign of duplication region detected by NIPT: $5.29 \mathrm{Mb}$ at chromosome 2q32.3q33.1. Because the gain in copy number go off scale, it could be speculated that this duplication is maternal in origin. All-Alll. CMA as indicated by copy number state using the Affymetrix Cytoscan $750 \mathrm{~K}$. The chromosome duplication region of the fetus and pregnant women from 195,365,474 to 199,646,763 bp at chromosome 2 is indicated by bule box. The upper axis indicates the log 2 ratio, where 2 illustrates the ratio of each SNP compared to diploid individuals in chromosome (a log2 ratio of 0 means an actual ratio of 1). Additionally, the lower abscissa axis indicates the value of B allele frequency (BAF). BAF may have three values in a diploid individual. While the BAF with four values and the increased log2 ratio indicated duplication regions. AIV The CMA result of the pregnant women's husband. BI NIPT of peripheral blood from a pregnant woman shows gain in copy number at chromosome 11q21q25 with $40.09 \mathrm{Mb}$, arrow indicates the sign of duplication region detected by NIPT. BII The CMA result of the fetus shows the chromosome duplication region from 99,364,342 to 134,937,416 bp at chromosome 11q22.1q25 by bule box. BIII-BIV. The CMA results of the parents revealed a de novo $35.57 \mathrm{Mb}$ duplication at 11q22.1q25 (chromosome position: 99,364,342134,937,416)

of labour, a CNV-seq test of placental tissue showed T21 mosaicism, implying that mosaicism was the main cause of the false negative in this case.
In addition, we analysed the detection efficiency of SCA in NIPT and found a PPV of $40.22 \%$ for all SCAs. The PPVs of 45,X, 47,XXY, 47,XXX, and 47,XYY were $17.50 \%, 56.52 \%, 55.56 \%$, and $63.64 \%$, respectively. NIPT 
Table 3 The distribution of true positive CNVs in different chromosomes

\begin{tabular}{|c|c|c|c|c|c|c|c|c|}
\hline \multirow[t]{3}{*}{ Chr } & \multicolumn{3}{|c|}{ CNVs length } & \multicolumn{2}{|c|}{ CNV gain or loss } & \multicolumn{3}{|l|}{ CCNV } \\
\hline & $<5$ & Within $5-10 \mathrm{Mb}$ & $>10$ & CNV & CNV & NIPT & NIPT true & NIPT false \\
\hline & $\mathrm{Mb}$ & & $\mathrm{Mb}$ & Gain & Loss & positive & positive & positive \\
\hline Chr1 & 3 & 0 & 0 & 2 & 1 & 3 & 1 & 2 \\
\hline Chr2 & 3 & 1 & 0 & 2 & 2 & 4 & 3 & 1 \\
\hline Chr3 & 2 & 1 & 0 & 3 & 0 & 3 & 3 & 0 \\
\hline Chr4 & 1 & 0 & 0 & 0 & 1 & 1 & 1 & 0 \\
\hline Chr 5 & 3 & 1 & 2 & 0 & 6 & 6 & 0 & 6 \\
\hline Chr6 & 2 & 1 & 0 & 2 & 1 & 3 & 1 & 2 \\
\hline Chr7 & 0 & 1 & 0 & 0 & 1 & 1 & 0 & 1 \\
\hline Chr8 & 2 & 1 & 0 & 1 & 2 & 3 & 2 & 1 \\
\hline Chr9 & 0 & 1 & 0 & 1 & 0 & 1 & 0 & 1 \\
\hline Chr10 & 1 & 1 & 0 & 0 & 2 & 2 & 1 & 1 \\
\hline Chr11 & 1 & 0 & 1 & 2 & 0 & 2 & 2 & 0 \\
\hline Chr12 & 1 & 0 & 0 & 0 & 1 & 1 & 1 & 0 \\
\hline Chr13 & 2 & 1 & 0 & 1 & 2 & 3 & 1 & 2 \\
\hline Chr14 & 0 & 0 & 0 & 0 & 0 & 0 & 0 & 0 \\
\hline Chr15 & 1 & 2 & 0 & 1 & 2 & 3 & 2 & 1 \\
\hline Chr16 & 3 & 0 & 0 & 2 & 1 & 3 & 2 & 1 \\
\hline Chr17 & 2 & 0 & 0 & 1 & 1 & 2 & 1 & 1 \\
\hline Chr18 & 4 & 1 & 1 & 3 & 3 & 6 & 4 & 2 \\
\hline Chr19 & 0 & 0 & 0 & 0 & 0 & 0 & 0 & 0 \\
\hline Chr20 & 1 & 0 & 1 & 1 & 1 & 2 & 0 & 2 \\
\hline Chr21 & 0 & 0 & 0 & 0 & 0 & 0 & 0 & 0 \\
\hline Chr22 & 1 & 1 & 0 & 1 & 1 & 2 & 0 & 2 \\
\hline Total & 33 & 13 & 5 & 23 & 28 & 51 & 25 & 26 \\
\hline
\end{tabular}

had relatively high PPVs for 47,XXY, 47,XXX, and 47,XYY and a low PPV for 45,X. The following were considered as possible explanations: (1) the high GC content of the $\mathrm{X}$ chromosome led to poor amplification efficiency; (2) X and Y chromosome sequences are highly homologous and prone to deviation in sequence comparison; and (3) random inactivation of the $\mathrm{X}$ chromosome. In conclusion, NIPT is suitable for the detection of SCA, but results for 45 , X should be treated with caution.

There were 69 cases of other chromosome aneuploidy abnormalities in this study, including 2 true positive cases, 39 false positive cases, and 28 undetermined cases. The PPV of other chromosome aneuploidy abnormalities was $4.88 \%$. Two true positive cases showed a duplication on chr2. The amniotic fluid karyotype in one case was $\operatorname{mos} 47, \mathrm{XX},+2[11] / 46, \mathrm{XX}[47]$; the CMA result showed $60-70 \%$ chromosomal duplication mosaicism on chr2, with no abnormality on ultrasound. The amniotic fluid karyotype for one case was 46,XX, and CMA showed chromosomal duplication mosaicism on chr2 of $\sim 30 \%$, with no ultrasound abnormality. After careful selection, 2 pregnant women chose to continue the pregnancy; these
2 children are approximately 1 year old, with normal intelligence, growth and development. Overall, the trophoblast cells detected by NIPT and exfoliated cells detected in amniotic fluid do not completely represent the condition of the foetus. In clinical practice, especially in mosaicism, ultrasound needs to be added for comprehensive evaluation. Among the cases, T7 was most frequent, with 8 cases in total, followed by T8 and T16, though no abnormality was found by amniotic fluid verification or ultrasound. However, Qi et al. [24-26] suggested that T7, $\mathrm{T} 8$, and T16 cases should almost certainly be interpreted as placental mosaicism and as confined placental mosaicism if accompanied by normal amniocentesis data. The possible causes of false positives in NIPT are as follows. (1) The accuracy of NIPT results depend not only on the detection ability but also on the incidence of disease [27]. As other chromosomal aneuploidies are rare, the PPVs of other chromosomal aneuploidies screened by NIPT were not high, which may be the reason why the PPVs of T13 and T18 were significantly lower than that of T21. (2) Chromosomal abnormalities only occurring in the placenta and not in the foetus are called confined placental 
Table 4 Classification of true positive CNV and pregnancy outcome

\begin{tabular}{|c|c|c|c|c|c|c|}
\hline Patients & NIPT & CMA & CNV & Inheritance & $\begin{array}{l}\text { Pregnancy } \\
\text { outcome }\end{array}$ & $\begin{array}{l}\text { Gestation at the } \\
\text { time of therapeutic } \\
\text { abortion }\end{array}$ \\
\hline Case 1 & $\begin{array}{l}\text { 8p23.2p23.3, deletion, } \\
5.2 \mathrm{M}\end{array}$ & $\begin{array}{l}\text { 8p23.2p23.3, dele- } \\
\text { tion, } 6.0 \mathrm{M}\end{array}$ & Pathogenic & de novo & Therapeutic abortion & $23^{+2} \mathrm{~W}$ \\
\hline Case 2 & $\begin{array}{l}12 \mathrm{p} 12.1 \mathrm{p} 12.2 \text {, deletion, } \\
4.2 \mathrm{M}\end{array}$ & $\begin{array}{l}12 \mathrm{p} 12.1 \mathrm{p} 12 ., \text { dele- } \\
\text { tion, } 4.13 \mathrm{M}\end{array}$ & Pathogenic & not determined & Therapeutic abortion & $21^{+5} \mathrm{~W}$ \\
\hline Case 3 & $\begin{array}{l}\text { 18q12.3, duplication, } \\
2.2 \mathrm{M}\end{array}$ & $\begin{array}{l}\text { 18q12.3, duplication, } \\
1.51 \mathrm{M}\end{array}$ & VOUS & Not determined & Delivery, normal & \\
\hline Case 4 & $\begin{array}{l}15 q 13.2 q 13.3 \text {, deletion, } \\
2.1 \mathrm{M}\end{array}$ & $\begin{array}{l}15 q 13.2 q 13.3 \text {, dele- } \\
\text { tion, } 1.34 \mathrm{M}\end{array}$ & Pathogenic & de novo & Therapeutic abortion & $23^{+4} \mathrm{~W}$ \\
\hline Case 5 & $\begin{array}{l}11 \mathrm{p} 14.2 \mathrm{p} 14.3 \text {, duplica- } \\
\text { tion, } 3.85 \mathrm{M}\end{array}$ & $\begin{array}{l}\text { 11p14.2p14.3, dupli- } \\
\text { cation, } 3.59 \mathrm{M}\end{array}$ & VOUS & $\begin{array}{l}\text { Inherited from the } \\
\text { father }\end{array}$ & Delivery, normal & \\
\hline Case 6 & $\begin{array}{l}11 \mathrm{q} 22.1 \mathrm{q} 25, \text { duplica- } \\
\text { tion, } 40.09 \mathrm{M}\end{array}$ & $\begin{array}{l}\text { 11q22.1q25, duplica- } \\
\text { tion, } 35.57 \mathrm{M}\end{array}$ & Pathogenic & de novo & $\begin{array}{l}\text { Head deformity } \\
\text { (ultrasound), thera- } \\
\text { peutic abortion }\end{array}$ & $22^{+1} \mathrm{~W}$ \\
\hline Case 7 & $\begin{array}{l}16 \mathrm{p} 13.11 \text {, duplication, } \\
2.5 \mathrm{M}\end{array}$ & $\begin{array}{l}\text { 16p13.11, duplica- } \\
\text { tion, } 1.64 \mathrm{M}\end{array}$ & $\begin{array}{l}\text { Likely pathogenic } \\
\text { (nonpenetrance) }\end{array}$ & Not determined & Unknown & \\
\hline Case 8 & 10q21.1, deletion, 2.1 M & $\begin{array}{l}10 \mathrm{q} 21.1 \text {, deletion, } \\
2.13 \mathrm{M}\end{array}$ & VOUS & Not determined & Delivery, normal & \\
\hline Case 9 & $\begin{array}{l}\text { 2q32.3q33.1, duplica- } \\
\text { tion, } 5.29 \mathrm{M}\end{array}$ & $\begin{array}{l}\text { 2q32.3q33.1, duplica- } \\
\text { tion, } 4.28 \mathrm{M}\end{array}$ & VOUS & $\begin{array}{l}\text { Inherited from the } \\
\text { mother }\end{array}$ & Delivery, normal & \\
\hline Case 10 & $\begin{array}{l}\text { 18q22.3q23, duplica- } \\
\text { tion, } 5.45 \mathrm{M}\end{array}$ & $\begin{array}{l}\text { 18q22.3q23, duplica- } \\
\text { tion, } 6.04 \mathrm{M}\end{array}$ & vous & $\begin{array}{l}\text { Inherited from the } \\
\text { mother }\end{array}$ & $\begin{array}{l}\text { Head deformity } \\
\text { (ultrasound), thera- } \\
\text { peutic abortion }\end{array}$ & $26^{+6} \mathrm{~W}$ \\
\hline Case 11 & $\begin{array}{l}\text { 4p14p15.1, deletion, } \\
3.6 \mathrm{M}\end{array}$ & $\begin{array}{l}\text { 4p14p15.1, deletion, } \\
3.32 \mathrm{M}\end{array}$ & VOUS & Not determined & Delivery, normal & \\
\hline Case 12 & $\begin{array}{l}\text { 13q33.1q34, deletion, } \\
9.4 \mathrm{M}\end{array}$ & $\begin{array}{l}\text { 13q33.1q34, deletion, } \\
9.22 \mathrm{M}\end{array}$ & Pathogenic & de novo & $\begin{array}{l}\text { Craniofacial malfor- } \\
\text { mation (ultrasound), } \\
\text { therapeutic abortion }\end{array}$ & $25^{+1} \mathrm{~W}$ \\
\hline Case 13 & $\begin{array}{l}\text { 1q21.1q21.2, duplica- } \\
\text { tion, 3.0 M }\end{array}$ & $\begin{array}{l}\text { 1q21.1q21.2, duplica- } \\
\text { tion, } 1.71 \mathrm{M}\end{array}$ & $\begin{array}{l}\text { Pathogenic (incom- } \\
\text { plete penetrance) }\end{array}$ & $\begin{array}{l}\text { Inherited from the } \\
\text { mother }\end{array}$ & Therapeutic abortion & $24^{+6} \mathrm{~W}$ \\
\hline Case 14 & $\begin{array}{l}\text { 3q26.33q27.1, duplica- } \\
\text { tion, } 3.35 \mathrm{M}\end{array}$ & $\begin{array}{l}\text { 3q26.33q27.1, dupli- } \\
\text { cation, 3.29 M }\end{array}$ & VOUS & Not determined & Delivery, normal & \\
\hline Case 15 & $\begin{array}{l}\text { 15q11.2q13.1, duplica- } \\
\text { tion, } 6 \mathrm{M}\end{array}$ & $\begin{array}{l}\text { 15q11.2q13.1, dupli- } \\
\text { cation, } 5.24 \mathrm{M}\end{array}$ & Pathogenic & Not determined & Therapeutic abortion & \\
\hline Case 16 & $\begin{array}{l}\text { 18q12.3q22.3, duplica- } \\
\text { tion, } 28.6 \mathrm{M}\end{array}$ & $\begin{array}{l}\text { 18q12.3q22.3, dupli- } \\
\text { cation, } 30.59 \mathrm{M}\end{array}$ & Pathogenic & Not determined & $\begin{array}{l}\text { Head deformity and } \\
\text { cheilopalatognathus } \\
\text { (ultrasound), thera- } \\
\text { peutic abortion }\end{array}$ & $23^{+5} \mathrm{~W}$ \\
\hline Case 17 & $\begin{array}{l}\text { 16p13.11p12.3, dupli- } \\
\text { cation, 3.6 M }\end{array}$ & $\begin{array}{l}\text { 16p13.11 p12.3, } \\
\text { duplication, } 2.67 \mathrm{M}\end{array}$ & $\begin{array}{l}\text { Likely pathogenic } \\
\text { (nonpenetrance) }\end{array}$ & not determined & Delivery, normal & \\
\hline Case 18 & $\begin{array}{l}\text { 3p26.3, duplication, } \\
2.5 \mathrm{M}\end{array}$ & $\begin{array}{l}\text { 3p26.3, duplication, } \\
2.21 \mathrm{M}\end{array}$ & VOUS & $\begin{array}{l}\text { Inherited from the } \\
\text { mother }\end{array}$ & Delivery, normal & \\
\hline Case 19 & $\begin{array}{l}\text { 2q12.1q12.3, duplica- } \\
\text { tion, } 2.5 \mathrm{M}\end{array}$ & $\begin{array}{l}\text { 2q12.1-12.3, duplica- } \\
\text { tion, } 2.51 \mathrm{M}\end{array}$ & VOUS & Not determined & Delivery, normal & \\
\hline Case 20 & 17p12, deletion, $2.5 \mathrm{M}$ & $\begin{array}{l}17 \mathrm{p} 12 \text {, deletion, } \\
1.42 \mathrm{M}\end{array}$ & Pathogenic & $\begin{array}{l}\text { Inherited from the } \\
\text { mother }\end{array}$ & Delivery, normal & \\
\hline Case 21 & $\begin{array}{l}6 \mathrm{p} 12.1 \mathrm{p} 12.3 \text {, duplica- } \\
\text { tion, } 4.6 \mathrm{M}\end{array}$ & $\begin{array}{l}6 \mathrm{p} 12.1 \mathrm{p} 12.3 \text {, duplica- } \\
\text { tion, } 4.36 \mathrm{M}\end{array}$ & VOUS & $\begin{array}{l}\text { Inherited from the } \\
\text { mother }\end{array}$ & Delivery, normal & \\
\hline Case 22 & 18q12.2, deletion, $2.5 \mathrm{M}$ & $\begin{array}{l}18 q 12.2 \text {, deletion, } \\
1.06 \mathrm{M}\end{array}$ & VOUS & Not determined & Therapeutic abortion & $23^{+3} \mathrm{~W}$ \\
\hline Case 23 & 2q13, deletion, $2 \mathrm{M}$ & $\begin{array}{l}\text { 2q13, deletion, } \\
2.12 \mathrm{M}\end{array}$ & $\begin{array}{l}\text { Likely pathogenic } \\
\text { (nonpenetrance) }\end{array}$ & $\begin{array}{l}\text { Inherited from the } \\
\text { mother }\end{array}$ & Delivery, normal & \\
\hline Case 24 & $\begin{array}{l}8 \text { p21.3p22, deletion, } \\
5.21\end{array}$ & $\begin{array}{l}\text { 8p21.3p2, deletion, } \\
3.81 \mathrm{M}\end{array}$ & VOUS & Not determined & Delivery, normal & \\
\hline
\end{tabular}


Table 4 (continued)

\begin{tabular}{llllll}
\hline Patients NIPT & CMA & CNV & Inheritance & $\begin{array}{l}\text { Pregnancy } \\
\text { outcome }\end{array}$ & $\begin{array}{l}\text { Gestation at the } \\
\text { time of therapeutic } \\
\text { abortion }\end{array}$ \\
\hline Case 25 & $\begin{array}{l}3 q 26.32 q 28, \text { duplica- } \\
\text { tion, 9.61 M }\end{array}$ & $\begin{array}{l}3 q 26.32 q 28, \text { duplica- } \\
\text { tion, } 9.61 \mathrm{M}\end{array}$ & Pathogenic & de novo & $\begin{array}{l}\text { Facial and cardiac } \\
\text { abnormalities (ultra- } \\
\text { sound), therapeutic } \\
\text { abortion }\end{array}$ \\
\end{tabular}

mosaicism (CPM) [28]. The foetal free DNA detected by NIPT mainly originates from placental trophoblast cells; thus, CPM is another main reason for false positive cases, with an incidence of approximately 1-2\% [8]. (3) The false positive rate of NIPT might be due to a trisomy rescue mechanism, i.e., uniparental disomy (UPD) [29]. In this study, one case showed a duplication on chr16. The karyotype based on amniotic fluid was 46,XY, and the CMA results showed $5.91 \mathrm{Mb}$ loss of heterozygosity in the region of 16p13.3, which did not rule out the possibility of UPD on chr16. It is clear that chr.6, 7, 11, 14, 15, and 20 are involved in imprinting syndrome. Considering that there is no known imprinted gene on chr16, the pregnant woman finally chose to continue the pregnancy after combining high-level ultrasound monitoring. In conclusion, other chromosomal aneuploidy abnormalities indicated by NIPT usually had favourable pregnancy outcomes in this study. In general, NIPT should not be recommended for screening of other chromosomal aneuploidies, and invasive testing should be used cautiously.

Because of the high incidence of MMS (1.00-1.70\%), Liang et al. [13] suggested that extended NIPT combined with ultrasound can be used as an independent system for foetal MMS screening. Overall, the accuracy of detecting MMS by NIPT may be affected by many factors, such as the cffDNA content, interference of maternal CNVs, and interference of foetal placenta mosaicism. At present, the accuracy of detection is effectively improved by GC correction comparison and sliding window analysis of data. MMS in this study also had an excellent PPV (49.02\%); the PPVs of CNVs with $<5 \mathrm{Mb}, 5-10 \mathrm{Mb}$, and $>10 \mathrm{Mb}$ were $54.55 \%$, $38.46 \%$, and $40.00 \%$, respectively. According to ACMG standards, CNVs can be divided into five categories: pathogenic, likely pathogenic, uncertain significance, likely benign, and benign. Among the 25 true positive cases, 10 were pathogenic, 3 were likely pathogenic, and 12 were of uncertain significance. The condition of pathogenic CNVs in 10 cases may be summarized as follows. (1) There were 4 cases with abnormal ultrasound results, and the women chose therapeutic abortion. (2) There were 4 cases without abnormal ultrasound results; considering that pathogenicity was mostly related to developmental retardation, mental retardation, language retardation, attention deficit hyperactivity disorder or autistic behaviour, the pregnant women also chose therapeutic abortion. (3) There was 1 case of a $1.42-\mathrm{Mb}$ deletion of $17 \mathrm{p} 12$, the pathogenicity of which is related to hereditary pressure susceptible peripheral neuropathy. CMA of the parents confirmed that it was inherited from the mother, and no abnormality was found on ultrasound. After careful consideration, the woman chose to continue the pregnancy and delivered a healthy baby. (4) There was 1 case with a $1.71-\mathrm{Mb}$ duplication of $1 \mathrm{q} 21.1 \mathrm{q} 21.2$, which is associated with 1q21.1 microduplication syndrome and mainly manifests as mild to moderate mental retardation, autism, attention-deficit hyperactivity disorder, giant, etc. The penetrance rate of this syndrome is approximately $29.1 \%$. CMA of the parents confirmed that it was inherited from the mother, and no abnormality was found on ultrasound. After careful consideration, the woman chose therapeutic abortion given the $29 \%$ risk of penetrance. The condition of likely pathogenic CNVs in 3 cases may be summarized as follows. (1) One patient refused to be followed up, and the pregnancy outcome was unknown. (2) There was 1 case of a $2.67-\mathrm{Mb}$ duplication of $16 \mathrm{p} 13.11 \mathrm{p} 12.3$, which is a susceptible area for neurocognitive diseases. An individual carrying this duplication might manifest mental retardation, developmental retardation, autism, attention deficit hyperactivity disorder, etc. The penetrance rate of this syndrome is approximately $5-10 \%$. Considering the low penetrance rate and normal ultrasound result, the woman chose to continue the pregnancy, and a healthy baby was born. (3) There was 1 case with a $2.12 \mathrm{Mb}$ deletion of $2 \mathrm{q} 13$. According to CLINGEN, the deletion score of this region is 2 . Individuals with this deletion possibly manifest mental retardation, autism, attention deficit hyperactivity disorder, congenital heart abnormality, mild facial abnormalities, etc. CMA of the parents confirmed that it was inherited from the mother. The woman chose to continue the pregnancy, and a healthy baby was born. CNVs of uncertain significance were identified in 12 cases, as follows. (1) Eleven cases without abnormal ultrasound results. After careful consideration, 10 patients chose to continue the pregnancy, and healthy babies were born; however, 1 woman chose induction of labour. (2) There was 1 case with a 6.04-Mb duplication of 18q22.3q23. CMA of the parents confirmed that it was inherited from the mother. The woman chose therapeutic abortion because of cranial abnormalities on ultrasound. 
Thus, among the 25 true positive cases, 13 had good pregnancy outcomes, suggesting that (1) the pathogenicity of CNV should be determined, (2) the detection scope should be limited to definite chromosome microdeletion and microduplication syndrome and (3) comprehensive analysis of ultrasound and medical history should be combined to reduce unnecessary invasive diagnostic measures.

\section{Conclusions}

This is a systematic report of NIPT for foetal CNV detection using a large sample size. NIPT based on NGS is a potential method for foetal CNV detection, especially with further investigation about a large number of clinical samples and long-term detailed clinical followed-up. At present, extended NIPT combined with ultrasound is effective for screening of MMS, but NIPT should not be recommended for whole-chromosome aneuploidy screening.

\section{Acknowledgements}

We would like to thank our patients for agreeing to donate their personal data for our study and to have these data published.

\section{Authors' contributions}

All authors participated in the study and manuscript preparation. All authors read and approved the final manuscript.

\section{Funding}

Financial supported by the Key Technologies Research and Development Program of Anhui Province, China (No: 202004j07020004).

\section{Availability of data and materials}

The datasets used or analysed during the current study are available from the corresponding author on reasonable request.

\section{Declarations}

\section{Ethics approval and consent to participate}

The study was approved by the Hospital Ethics Committee of Anhui Maternity and Child Health Care Hospital (No: 20170681), and all methods were carried out in accordance with relevant guidelines and regulations. Each patient signed informed consent prior to study enrolment.

\section{Consent for publication}

Not applicable.

\section{Competing interests}

The authors declare that they have no competing interests.

\section{Author details}

${ }^{1}$ Affiliated Maternity and Child Health Hospital of Anhui Medical University, Maternity and Child Health Hospital of Anhui Province, Hefei, China. ${ }^{2}$ Beijing Genomics Institute, Beijing, China.

Received: 6 November 2020 Accepted: 16 November 2021

Published online: 11 December 2021

\section{References}

1. Lo YM, Corbetta N, Chamberlain PF, Rai V, et al. Presence of fetal DNA in maternal plasma and serum. Lancet. 1997;350(9076):485-7.

2. Minear MA, Lewis C, Pradhan S, et al. Global perspectives on clinical adoption of NIPT. Prenat Diagn. 2015;35(10):959-67.
3. Song Y, Liu C, Qi H, et al. Liu J. Noninvasive prenatal testing of fetal aneuploidies by massively parallel sequencing in a prospective Chinese population. Prenat Diagn. 2013;33(7):700-6.

4. Bianchi DW, Parker RL, Wentworth J, et al. DNA sequencing versus standard prenatal aneuploidy screening. N Engl J Med. 2014;370(9):799-808.

5. Mazloom AR, Džakula Ž, Oeth P, et al. Maeder M, McLennan G, Meschino W, Palomaki GE, Canick JA, Deciu C. Noninvasive prenatal detection of sex chromosomal aneuploidies by sequencing circulating cell-free DNA from maternal plasma. Prenat Diagn. 2013;33(6):591-7.

6. Samango-Sprouse C, Banjevic M, Ryan A, et al. SNP-based non-invasive prenatal testing detects sex chromosome aneuploidies with high accuracy. Prenat Diagn. 2013;33(7):643-9.

7. Wapner RJ, Martin CL, Levy B, et al. Chromosomal microarray versus karyotyping for prenatal diagnosis. N Engl J Med. 2012;367(23):2175-84.

8. Grati FR, Malvestiti F, Ferreira JC, et al. Fetoplacental mosaicism: potential implications for false-positive and false-negative noninvasive prenatal screening results. Genet Med. 2014;16(8):620-4.

9. Yu SC, Jiang P, Choy KW, et al. Noninvasive prenatal molecular karyotyping from maternal plasma. PLoS One. 2013;8(4):e60968.

10. Srinivasan A, Bianchi DW, Huang $H$, et al. Noninvasive detection of fetal subchromosome abnormalities via deep sequencing of maternal plasma. Am J Hum Genet. 2013;92(2):167-76.

11. Wapner RJ, Babiarz JE, Levy B, et al. Expanding the scope of noninvasive prenatal testing: detection of fetal microdeletion syndromes. Am J Obstet Gynecol. 2015;212(3):332.

12. Chen $Y, Y u Q$, Mao X, et al. Noninvasive prenatal testing for chromosome aneuploidies and subchromosomal microdeletions/microduplications in a cohort of 42,910 single pregnancies with different clinical features. Hum Genomics. 2019;13(1):60

13. Liang D, Cram DS, Tan H, et al. Clinical utility of noninvasive prenatal screening for expanded chromosome disease syndromes. Genet Med. 2019;21(9):1998-2006.

14. Hongge Li Yu, Lei HZ, et al. The application of NIPT using combinatorial probe-anchor synthesis to identify sex chromosomal aneuploidies (SCAs) in a cohort of 570 pregnancies. Mol Cytogenet. 2018;11:59.

15. Rose NC, Benn P, Milunsky A. Current controversies in prenatal diagnosis 1: should NIPT routinely include microdeletions/microduplications? Prenat Diagn. 2016;36(1):10-4.

16. Evans MI, Wapner RJ, Berkowitz RL. Noninvasive prenatal screening or advanced diagnostic testing: caveat emptor. Am J Obstet Gynecol. 2016;215(3):298-305.

17. Gregg AR, Skotko BG, Benkendorf JL, et al. Noninvasive prenatal screening for fetal aneuploidy, 2016 update: a position statement of the American College of Medical Genetics and Genomics. Genet Med. 2016;18(10):1056-65.

18. Genomics (ACMG) Professional Practice and Guidelines Committee. Addendum: Array-based technology and recommendations for utilization in medical genetics practice for detection of chromosomal abnormalities. Genet Med. 2020.

19. Niederstrasser SL, Hammer K, Möllers M, et al. Fetal loss following invasive prenatal testing: a comparison of transabdominal chorionic villus sampling, transcervical chorionic villus sampling and amniocentesis. J Perinat Med. 2017:45(2):193-8.

20. Verma IC, Dua-Puri R, Bijarnia-Mahay S. ACMG 2016 update on noninvasive prenatal testing for fetal aneuploidy: implications for India. J Fetal Med. 2017:4:1-6.

21. Neofytou MC, Tsangaras K, Kypri E, et al. Targeted capture enrichment assay for non-invasive prenatal testing of large and small size sub-chromosomal deletions and duplications. PLoS One. 2017;12(2):e0171319.

22. Yaron $Y$, Jani J, Schmid M, et al. Current status of testing for microdeletion syndromes and rare autosomal trisomies using cell-free DNA technology. Obstet Gynecol. 2015;126(5):1095-9.

23. Norton ME, Jacobsson B, Swamy GK, et al. Cell-free DNA analysis for noninvasive examination of trisomy. N Engl J Med. 2015;372(17):1589-97.

24. Qi Y, Yang J, Hou Y, et al. The significance of trisomy 7 mosaicism in noninvasive prenatal screening. Hum Genomics. 2019;13(1):18.

25. Benn P. Trisomy 16 and trisomy 16 Mosaicism: a review. Am J Med Genet. 1998;79(2):121-33.

26. Cassina M, Calò A, Salviati L, Alghisi A, Montaldi A, Clementi M. Prenatal detection of trisomy 8 mosaicism: Pregnancy outcome and follow up 
of a series of 17 consecutive cases. Eur J Obstet Gynecol Reprod Biol. 2018;221:23-7.

27. Lutgendorf MA, Stoll KA, Knutzen DM, et al. Noninvasive prenatal testing: limitations and unanswered questions. Genet Med. 2014 Apr;16(4):281-5.

28. Mardy A, Wapner RJ. Confined placental mosaicism and its impact on confirmation of NIPT results. Am J Med Genet C Semin Med Genet. 2016;172(2):118-22.

29. Pan M, Li FT, LiY, et al. Discordant results between fetal karyotyping and non-invasive prenatal testing by maternal plasma sequencing in a case of uniparental disomy 21 due to trisomic rescue. Prenat Diagn. 2013;33(6):598-601.

\section{Publisher's Note}

Springer Nature remains neutral with regard to jurisdictional claims in published maps and institutional affiliations.

- fast, convenient online submission

- thorough peer review by experienced researchers in your field

- rapid publication on acceptance

- support for research data, including large and complex data types

- gold Open Access which fosters wider collaboration and increased citations

- maximum visibility for your research: over $100 \mathrm{M}$ website views per year

At BMC, research is always in progress.

Learn more biomedcentral.com/submissions 